\title{
Applying a food processing-based classification system to a food guide: a qualitative analysis of the Brazilian experience
}

\author{
Vanessa Fernandes Davies', Jean-Claude Moubarac ${ }^{1,2}$, Kharla Janinny Medeiros ${ }^{3}$ and \\ Patricia Constante Jaime ${ }^{1, *}$ \\ 'Universidade do Estado de São Paulo, Faculdade de Saúde Pública, Departamento de Nutrição, Avenida \\ Dr Arnaldo 715, 2 andar, Cerqueira Cesar CEP 01246904, São Paulo, SP, Brazil: ${ }^{2}$ Département de Nutrition, \\ Université de Montréal, Montréal, Québec, Canada: ${ }^{3}$ Universidade Federal de Santa Catarina, Departamento de \\ Nutrição/NUPPRE - Comportamento Alimentar, Florianópolis, SC, Brazil
}

Submitted 28 October 2016: Final revision received 26 April 2017: Accepted 27 June 2017: First published online 29 August 2017

\begin{abstract}
Objective: The present paper aimed to identify the stakeholders, as well as their arguments and recommendations, in the debate on the application of a food processing-based classification system to the new Brazilian Food Guide.

Design: Qualitative approach; an analysis was made of documents resulting from the consultation conducted for the development of the new Brazilian Food Guide, which uses the NOVA classification for its dietary recommendations. A thematic matrix was constructed and the resulting themes represented the main points for discussion raised during the consultation.

Setting: Brazil.

Subjects: Actors from academia, government and associations/unions/professional bodies/organizations related to the area of nutrition and food security; non-profit institutions linked to consumer interests and civil society organizations; organizations, associations and food unions linked to the food industry; and individuals. Results: Four themes were identified: (i) conflicting paradigms; (ii) different perceptions about the role and need of individuals; (iii) we want more from the new food guide; and (iv) a sustainable guide.

Conclusions: There was extensive participation from different sectors of society. The debate generated by the consultation revealed two main conflicting opinions: a view aligned with the interests of the food industry and a view of healthy eating which serves the interests of the population. The first group was against the adoption of a food processing-based classification system in a public policy such as the new Brazilian Food Guide. The second group, although mostly agreeing with the new food guide, argued that it failed to address some important issues related to the food and nutrition agenda in Brazil.
\end{abstract}

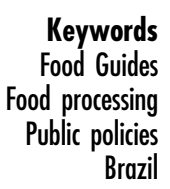

Food guides are important tools for the promotion of healthy eating and should be written in accessible language to facilitate understanding and their use by the general population, as well as by a wide range of people who work with food either directly (such as nutritionists and the food industry) or indirectly (such as journalists, teachers, etc. $)^{(1)}$. In addition, food guides can influence the development of food and agriculture policies, and serve as criteria for the implementation and evaluation of intervention programmes ${ }^{(2)}$.

The development of a food guide must take into account the social, economic and cultural characteristics of the country, as well as the nutritional and epidemiological profile of the population for which it is intended ${ }^{(1-3)}$. More than 100 countries have already developed, or are in the process of developing, food guides ${ }^{(1)}$. However, the majority of existing guides adopt a biological approach, following a reductionist model in which nutrition advice is generally reduced to food groups, food items and food constituents disconnected from the social and cultural practices of everyday life ${ }^{(4)}$. This biological approach has been widely criticized for disregarding a more comprehensive model of health, as well as for not taking account of the autonomy of individuals and the impact of their micro and macro environments on their food choices ${ }^{(4-7)}$.

To find a more sustainable and holistic approach to the issue of food and nutrition, in 2014 the new Brazilian Food Guide was published $^{(8)}$, replacing the 2006 Food Guide which had presented the first official dietary guidelines for the population over 2 years of age. The development of a new guide was necessary in the face of the many changes in health and nutrition experienced by the Brazilian 
population, including demographic (i.e. longer life expectancy), nutritional (increase of ultra-processed foods in the diet and rise in the number of overweight or obese people) and epidemiological (increased prevalence of chronic non-communicable diseases) ${ }^{(9,10)}$.

The latest version of the food guide for the Brazilian population is innovative in some respects, such as giving more value to the context in which food is eaten, to sociocultural values related to the act of eating, to different forms of knowledge and to the autonomy of individuals ${ }^{(7)}$. In addition, in light of the growing scientific evidence regarding the relationship between the consumption of ultra-processed foods, diet quality and nutritional status ${ }^{(11-13)}$, the new Brazilian Food Guide uses the NOVA classification ${ }^{(14)}$ which allows foods to be categorized based on the nature, extent and purpose of industrial processing.

Developing the new Brazilian Food Guide involved several steps, the last being a formal consultation allowing for the open participation of different sectors of society, which has been shown to be a democratic way of developing and improving public policies in Brazil ${ }^{(7)}$.

At the end of the public consultation, the participants' suggestions were analysed and a report ${ }^{(15)}$ was produced focusing on two main points: (i) a list of the main suggestions made by the participants; and (ii) suggestions which were accepted, partially accepted or not accepted. All decisions taken regarding the inclusion in the new guide of the participants' recommendations were justified based on the available scientific literature, the objective of the new guide, and the epidemiological and nutritional status of the Brazilian population. The report is available online (http://bvsms.saude.gov.br/bvs/publicacoes/guia_ alimentar_populacao_relatorio_final.pdf).

The analysis of consultations can provide valuable explanations as to why the proposed objectives of a programme/policy are being achieved or not, and can also be used as a way of identifying the different interests that influence the development of public policies. Understanding the interaction between different groups, institutions and economic interests is crucial to understanding the asymmetry of power and its impact on the success or failure of a particular policy and/or programme $e^{(16)}$.

The objective of the present study was to identify the stakeholders, as well as their arguments and recommendations, in the debate on the application of a food processing-based classification system to the new Brazilian Food Guide.

\section{Methodology}

\section{Type of study}

A qualitative study based on document analysis.

\section{Brazilian Food Guide}

Developing the Brazilian Food Guide took three years, and was prepared by the Ministry of Health, the Center for
Epidemiological Research in Nutrition and Health (NUPENS) at the University of São Paulo (USP) and the Pan American Health Organization. The following steps were taken, in this order: (i) workshops; and (ii) online consultation ${ }^{(7)}$. The final version of the new Brazilian Food Guide was published in 2014, following intensive revisions based on suggestions made during the consultation ${ }^{(8)}$.

\section{Data sources}

The documents analysed were taken from the open consultation conducted online (www.saude.gov.br/ consultapublica), which aimed to record the opinion of all those interested in offering suggestions or criticisms. Consultation No. 04/2014 was open for comments from 10 February to 7 May 2014, after which it was possible only to view the proposal and the contributions received ${ }^{(15)}$. The documents related to Public Consultation No. 04/2014 were formally requested from the General Council for Food and Nutrition at the Ministry of Health; they consisted of Final Consultation Report No. 04/2014 and digitalized documents from Consultation No. 04/2014, containing the individual contributions received online.

\section{Data analyses}

The thematic matrix technique ${ }^{(17)}$ was employed for the analyses, using the qualitative data analysis software NVivo version 11 (2015; QSR International, Doncaster, VIC, Australia) in order to organize the data and to facilitate the creation of the themes and categories. Two investigators coded the documents independently, using grounded theory. The thematic matrix technique involved the following steps: (i) extensive reading of the transcripts to become as familiar as possible with the data; (ii) rereading the transcripts to identify themes for the organization of data; (iii) indexing the themes within the transcripts; and (iv) removing data from the transcripts and transferring it to a matrix theme (each theme relating to statements from the participants). The matrix included the main ideas and perceptions of the individual on the theme.

\section{Participants}

The participants in the public consultation were grouped according to the organization or interests they represented: academia; government; associations/unions/professional bodies/organizations related to the area of nutrition and food security; non-profit institutions linked to consumer interests and civil society organizations; organizations, associations and food unions linked to the food industry; and individuals.

\section{Results}

A total of 3125 contributions were received from 431 different individuals/institutions. Participants in the consultation included: 201 representatives from academia; 102 individuals; fifty-eight representatives of the government; fifty-three associations, councils and bodies representing the areas of 
nutrition and food security, as well as non-profit organizations linked to consumer interests or civil society organizations; and seventeen organizations, associations and unions linked to the food industry.

Regarding the individuals, it was not possible to identify the area of work or the interests of all participants in this group, as they were not required to provide this information during the consultation. An online survey was conducted using the people's names to obtain this information and it was found that most of the individuals who took part in the consultation were nutrition students or professionals (about $80 \%$ ).

Of the 3125 contributions, 1706 were evaluated for the current study: 1287 contributions were excluded for reasons of repetition and 132 were excluded because they contained an error of some kind. Redundant contributions were most often focusing on material of Chapters 1,2 and 3, as well as on the final part of the guide in which the 'Ten Steps to a Healthy Diet' are presented. All redundant contributions were contrary to the proposals of the new guide.

Four themes were identified during the analysis: (i) Conflicting Paradigms; (ii) Different Perceptions about the Role and Need of Individuals; (iii) We Want More from the New Food Guide; and (iv) A Sustainable Guide.

The results of the analysis also allowed the participants in the public consultation to be divided into two final groups, this time according to the similarity of opinions/ suggestions: group 1 comprising participants whose opinions were against the new food guide; group 2 comprising participants who tended to agree with the ideas in the new food guide. Group 1 included some of the academics, as well as those from associations/unions/ professional bodies and organizations/associations and food unions linked to the food industry. Group 2 consisted of the remaining academics, as well as those from government, organizations related to the area of nutrition and food security, and non-profit institutions linked to consumer interests and civil society organizations. The opinions of individuals who did not represent any formal institution were roughly divided between group 1 and 2 .

\section{Theme 1: Conflicting Paradigms}

This theme was the one for which there was the largest participation of stakeholders ( $n$ 800). The participants' statements were generally of two types: (i) maintaining the previous version of the Brazilian Food Guide, which was based on recommendations for food groups according to their nutritional profile and recommendations regarding portions and the daily number of meals; or (ii) rejecting the old guide and completely accepting the healthy eating paradigms proposed by the new food guide including its reliance on the NOVA classification.

On one side of the dispute (defending the approach of the previous version of the food guide) were the food industry and food industry organizations/unions/associations.
Their opinions were to some extent shared by some associations and bodies representing the areas of nutrition, as well as by some academics and individuals. On the opposing side (a new approach to healthy eating) were the associations, councils and bodies representing the areas of nutrition and food security, as well as non-profit institutions linked to consumer interests and civil society organizations, government, and the remaining academics and individuals. Table 1 shows sample statements from the participants relating to this theme.

The question of which nutritional attributes should be promoted for healthy eating was discussed and the participants' statements ranged from a more holistic approach to a reductionist view of the act of eating. Several participants (associations, councils and bodies representing the areas of nutrition and food security; non-profit institutions linked to consumer interests and civil society organizations; government, academics and individuals) supported the new approach being proposed and emphasized the importance of going beyond the nutritional aspects of food. Another group of participants (food industry and food industry organizations/unions/associations; associations and bodies representing the areas of nutrition; the remaining academics and individuals) believed that the proposed food classification based on the purpose and extent of processing would undermine concepts already established in the science of nutrition. The contrast between these two opinions was clearly evident when the participants discussed the theme of culinary skills and the act of cooking. On the one hand, some were of the opinion that cooking is an emancipatory activity, an opportunity to address gender issues and the sharing of household activities. On the other hand, some had a more restricted view, focusing only on the nutritional aspects of cooking such as improving the nutritional quality of food and the bioavailability of nutrients, and some did not even recognize cooking as a practice related to the promotion of healthy eating.

The participants used both scientific and legal support for their arguments, citing regulatory bodies such as the National Health Surveillance Agency (ANVISA), the CODEX Alimentarius, FAO and WHO. Arguments related to the presence or absence of scientific evidence were used to question why the new food guide had failed to address certain issues, such as the number of meals per day and water consumption, as well as to question the new food classification. The arguments based on legal support were used primarily by those representing the interests of the food industry, specifically to challenge the new food classification proposed in the guide and to highlight the lack of information regarding food labelling.

Discourse around 'risk' was also used by the participants, mainly in two ways: first, those representing the food industry considered some traditional foods (such as 'feijoada') to be a health risk, and therefore disagreed with the new guide's recommendations that more of these foods should be consumed. Second, another group 
Table 1 Examples of statements from participants in the public consultation according to the context and argument used in Theme 1: Conflicting Paradigms

Context Argument used Examples of statements

Refers to the section of the new food guide which says: Holistic vision

'Food is more than nutrients'

Examples of statements

Medicalized view

Refers to the section of the new food guide which proposes a new classification of foods based on their industrial processing

Refers to the section of the new food guide that addresses food preparation

Refers to the new food guide section dealing with the issue of culinary skills in the 'Ten Steps to a Healthy Diet'

Refers to the section of the new food guide that addresses the topic of culinary skills and the act of cooking

Refers to the section of the new food guide that deals with the consumption of meat and eggs

Refers to the new food guide section that discusses the importance of preparing food at home and of maintaining regional and traditional foods of Brazilian culture (Government) choices.' (Academic)

Medicalized view food industry)

Medicalized view (Individual)

Medicalized view

The risk discourse
'Many people think of food as something just to satisfy the appetite or "eat this as it prevents such and such". But food brings much more than that, such as social belonging, which is something that makes you think about the subject.' (Individual)

'It is not confined to nutrients, addressing a global vision of food, the interaction with culture, behaviour, emotional relationships and the meaning of food. An interesting approach.'

Making nutrients the basis of our food could achieve the objectives of the guide more quickly, which would be to educate the public on the appropriate consumption of food and correct food

'We understand that the concept of healthy and unhealthy foods introduced in this guide should be replaced by foods with a high, medium or low nutritional profile.' (Organization linked to the

'The new definition proposed in the guide of what constitutes food goes against a principle universally used and scientifically supported, that food has in theory to add calories and/or nutrients for the functioning of the body.' (Organization linked to the food industry)

'We suggest the inclusion of information on dietary techniques that help improve the nutritional properties of food. For example, soaking beans and discarding the water before cooking not only serves to reduce the cooking time, but mainly to decrease the amount of anti-nutritional substances in food, as noted in the scientific literature.' (Academic)

'It does not show how to optimize the bioavailability of nutrients from in forms of food preparation:

'Develop, practise and share culinary skills. What does this have to do with healthy eating? Sharing recipes and having cooking skills does not make you healthier, on the contrary, recipes can be high in calories and have a high sugar content which further contributes to the increased rates of obesity and diabetes.' (Individual)

Holistic view 'Valuing culinary skills as an emancipatory practice - knowing how to prepare food increases autonomy, allows one to put into practice the technical information and widens the range of possibilities available to individuals. It is suggested that the act of cooking is included as an emancipatory practice, taking into account aspects of popular and symbolic wisdom related to the act of eating.' (Government)

'The valuing and the regain of culinary practice is a topic that requires a more comprehensive

'The valuing and the regain of culinary practice is a topic that requires a more comprehensive
approach. The ability to cook should be transmitted to people as an essential part of their training, regardless of gender.' (Food Security Council)

'In reality, cooking our own meals is only possible for the vast majority of families if domestic activities are shared, if there is physical and financial access to quality food, if the ability to cook is taught and learned, if the food prepared has greater social and symbolic value than any other; if we reverse the increasing elitism of cooking and this activity returns to being as basic as other daily activities such as brushing your teeth ...' (Food Security Council)

'There is compelling evidence that the excessive consumption of red meat may increase the risk of bowel cancer.' (Individual)

'The recommendation that the entire Brazilian population reduce the consumption of red meat, and replace it with foods like chicken, fish or eggs, may have a negative impact on the general consumption of haem iron ...' (Organization linked to the food industry)

The risk discourse 'Domestic processing, unchecked, can add undesirable substances to food (acrylamide,

mycotoxins) at levels greater than those present in processed foods, for which the parameters of heat exposure and quality control (including raw materials) are generally observed.' (Nutrition organization)

'We understand that it is risky to consider all preparations of traditional food as nutritionally balanced, the following examples have been noted: feijoada, goat buchada, among others ... (Organization linked to the food industry) 
(academics, individuals and the food industry) was concerned about the risk posed by the lack of certain recommendations in the new guide, for example with regard to water consumption. It is important to stress that it was not only the group opposed to the proposals of the new food guide who used the risk discourse.

\section{Theme 2: Different Perceptions about the Role and Need of Individuals}

This theme grouped together the participants' statements which reflected different perceptions about the role and the need of individuals who will use the new Brazilian Food Guide. Table 2 shows sample statements from the participants in this category.

The group of participants that represented the food industry, organizations and unions, as well as bodies and associations related to nutrition, claimed that due to the demands of modern society, people are often too busy to prepare their own food. People therefore need processed products and the food industry simply delivers what consumers demand.

Disagreeing with these statements, but without denying the impact of modern life on people's eating habits, other participants (individuals, academics, organizations related to food and nutrition security, non-profit organizations, government) praised the way in which the guide tackled the issue of processed foods.

Another recurring theme was the emphasis on the responsibility that people should take for their own diet, an argument used by some participants to justify their opposition to the approach taken by the guide to processed/ultra-processed foods and fast-food restaurants. Some were of the opinion that by advocating the decreased consumption of these foods, the new guide could undermine people's freedom of choice. Several participants stated that the lack of information on food labelling in the guide effectively represented a significant loss in terms of food choices, as labels could help people to choose healthier processed foods. This justification was used mainly to argue that there would be no need to reduce the consumption of these foods, but rather to educate people to read the labels.

The word 'consumer' was often used to refer to the target public of the guide. This nomenclature was common among the food industry and consumer rights organizations, but what was more noticeable was the use of this word by health professionals and bodies and organizations related to the area of nutrition, principally to imply that people were as responsible for their own food choices as any other choice. Disagreeing with the statements about the 'responsible individual' or 'consumers making their own choices', many participants referred to people as 'citizens'. Their emphasis was on the importance of the new guide to encourage autonomy, helping people to make more informed food choices and to be more critical of their food environment. 
Table 2 Examples of statements from participants in the consultation according to the context and argument used in Theme 2: Different Perceptions about the Role and Need of Individuals

\begin{tabular}{ll}
\hline Context & Argument used \\
\hline $\begin{array}{l}\text { Refers to the section of the new food guide } \\
\text { which says: 'Limit the use of ready-to-eat }\end{array}$ & $\begin{array}{c}\text { Individuals as responsible for their own } \\
\text { food choices }\end{array}$ \\
food products, avoiding them or consuming & $\begin{array}{l}\text { Individuals as consumers } \\
\text { them in small quantities as part of meals }\end{array}$ \\
based on fresh food and culinary & \\
preparations'
\end{tabular}

Refers to the section of the new food guide which says: "Buy food in markets or other places that sell varieties of fresh foods, and avoid places that only sell products ready for consumption'

Refers to the section of the new food guide which says: 'Giant Portions. Given the low cost of the ingredients, it is common for many ultra-processed products to be marketed in portions or giant portions or containers, at a price only slightly higher than regular portions or regular. These giant portions or containers thus increase the risk of consuming involuntary calories and therefore lead to a greater risk of obesity'

Refers to the section of the new food guide which says: 'Limit the use of ready-to-eat food products, avoiding them or consuming them in small quantities as part of meals based on fresh food and culinary preparations'

Refers to the section of the new food guide says: 'The information clarifies consumers and empowers citizens. Information is essential for consumers to make better choices and so that citizens act politically to conform environments promoters of healthy eating'
Individuals as responsible for their own food choices

Individuals as consumers

Individuals as responsible for their own food choices

Individuals as consumers

- opposing views of individuals as responsible for their own consumers

Individuals as responsible for their own food choices

Individuals as consumers

Individuals as citizens - divergence of individuals as responsible for their own food choices and as mere consumers
Examples of statements

'The document states that products labelled as ultra-processed convenience foods have transformed society, when what happened was obviously the opposite, i.e.: the food industries have been developing products for the new social reality.' (Academic)

'The change in Brazilian eating habits follows a global trend. Unfortunately, the daily routine of the general population does not allow for every meal to be prepared at home.' (Food industry)

'Despite knowing the time limits in our daily lives, it is interesting to include this reflection.' (Individual)

'This version of the guide is addressing the areas in which the current population should be careful ... as excessive use of oil, ready-made meals, the environment where they are bought ... it makes us rethink attitudes in the daily rush, as food is essential for life, from childhood to old age.' (Individual)

'In my opinion, it is not a good idea to advise people on where or how much food they should buy. Maybe those recommendations were interesting in the past, but I think it is time to change, to practise food education, to provide the knowledge for people to think for themselves, they decide for themselves, to be free ...' (Individual)

'It is worth noting that the amount consumed is a decision of the consumer and not the food itself, we do not perceive that the environment interferes in this decision.' (Organization linked to the food industry)

'Consumers should not allow the degree of processing to define their perception of food healthiness.' (Academic)

'The advance made by this guide came from recognizing the social construction process of food and health, recognizing the individual as the main influence on their own health and autonomous in their choices.' (Non-profit organization)

'Do not let it become the responsibility of the individual, but empower the individual to take social action.' (Non-profit organization)

\section{Theme 3: We Want More from the New Food Guide}

This category included the participants' comments on any content that they considered to be missing from the new guide. Table 3 shows sample statements from the participants in this category.

The participants positioned themselves at two extremes. On one side were the food industry and food organizations/unions, bodies and associations related to nutrition, as well as some academics and individuals, who showed greater concern about issues not found in the guide, such as: recommendations for water consumption; information regarding food labelling; the importance of physical activity; and recommendations for food portions.

On the other side were organizations related to food and nutrition security, non-profit organizations, government, and the other academics and individuals, who criticized the 
Table 3 Examples of statements from participants in the public consultation according to the context and argument used in Theme 3 : We Want More from the New Food Guide

\begin{tabular}{|c|c|c|}
\hline Context & Argument used & Examples of statements \\
\hline $\begin{array}{l}\text { Refers to the section of the new food guide which says: } \\
\text { 'Ten Steps to a Healthy Diet' }\end{array}$ & $\begin{array}{l}\text { In defence of more } \\
\text { technical content in } \\
\text { the new guide }\end{array}$ & $\begin{array}{l}\text { 'The guide is very good, but should emphasize water } \\
\text { consumption in the } 10 \text { steps, as the guide talks about } \\
\text { exercise, specifying amounts for consumption in } \\
\text { numbers and illustrations.' (Individual) }\end{array}$ \\
\hline \multirow[t]{2}{*}{$\begin{array}{l}\text { The sample quote included here appeared in the section: } \\
\text { 'The principles on which the guide is based' }\end{array}$} & $\begin{array}{l}\text { In defence of more } \\
\text { technical content in } \\
\text { the new guide }\end{array}$ & $\begin{array}{l}\text { 'The lack of guidance on the reading of food labelling in } \\
\text { the guide will mean a step backward and is out of line } \\
\text { with all current legislation on the subject, introduced in } \\
\text { order to promote healthy eating among the Brazilian } \\
\text { population.' (Individual) }\end{array}$ \\
\hline & $\begin{array}{l}\text { In defence of more } \\
\text { technical content in } \\
\text { the new guide }\end{array}$ & $\begin{array}{l}\text { 'We believe it is necessary to go more deeply into the } \\
\text { question of human rights, the human right to food and } \\
\text { the issue of access to food and nutrition security.' } \\
\text { (Government) } \\
\text { 'It is essential to refer to the existing policies in order to } \\
\text { strengthen them...' (Academic) }\end{array}$ \\
\hline $\begin{array}{l}\text { Refers to the section of the new food guide which says: 'The } \\
\text { advertising of ready-to-eat and ultra-processed products } \\
\text { dominates commercial food advertising, conveys } \\
\text { inaccurate and damaging information about food and } \\
\text { reaches mainly children and young people. Make it clear } \\
\text { to children and young people that the function of } \\
\text { advertising is essentially to increase the sale of products } \\
\text { and not to inform or, even less, educate people' }\end{array}$ & $\begin{array}{l}\text { In defence of more } \\
\text { technical content in } \\
\text { the new guide }\end{array}$ & $\begin{array}{l}\text { 'We need to regulate advertising, encourage people to } \\
\text { demand regulation.' (Individual) }\end{array}$ \\
\hline
\end{tabular}

absence of social and political issues in the guide, such as the human right to adequate food. This group also suggested adding information on food and nutrition security, and pointed out the lack of discussion related to existing nutrition and food policies in Brazil.

\section{Theme 4: A Sustainable Guide}

One of the principles of the new food guide was the sustainability of food systems. This category included the participants' statements which discussed, analysed or criticized this principle. Table 4 shows sample statements from the participants in this category.

The food industry and food organizations/unions, as well as the participants belonging to groups that covertly shared the same interests during the consultation, felt disadvantaged by the guide's approach and expressed themselves in defensive terms. The statements of these participants included emphasis on the advances in agriculture and the benefits for food production, and sustainability programmes promoted by the industry. There was an attempt to blame other industrial sectors for the damage to the environment, as well as to question the applicability of sustainable food systems in today's world.

Other participants (government, associations/unions/ professional bodies/organizations related to the area of nutrition and food security, and individuals) praised the new guide, but pointed out the need for it to deal with some issues more thoroughly, particularly to take a firmer stand on pesticides, GMO and organic food. There were also participants who strongly advocated the inclusion of recommendations related to vegetarianism, validating their position by adopting a broader view of the food system and its impact on the environment.

\section{Discussion}

Findings were captured in a conceptual framework that confirms previous knowledge of two different ways of approaching healthy eating: a biomedical model and a social sciences-oriented approach ${ }^{(18,19)}$. On the one hand, disagreeing with the proposals made in the new guide, were the food industry and food organizations/ unions, some bodies and associations related to nutrition, and some academics and individuals. The arguments used by this group to justify their interests showed a tendency to medicalize food consumption, supported by the authority of scientific evidence and a discourse around risk. They also stressed individuals' responsibility for their own food choices. On the other side of the discussion were the organizations related to food and nutrition security, non-profit organizations, government, as well as the other academics and individuals. Their views reflected the idea of a more integrated nutrition, giving more value to the social and cultural dimensions of eating, to the multiplicity of knowledge, to the promotion of more sustainable food systems and viewing people more as citizens, with co-responsibility for their own eating habits.

The medicalization argument was used by the participants especially to question the classification of foods based on the extent and purpose of their processing, and the qualitative approach proposed by the new guide. The medicalization of nutritional sciences views food as something primarily 
Table 4 Examples of statements from the consultation participants according to the context and argument used in Theme 4: A Sustainable Guide

Context
Refers to the section of the new
food guide which says: 'The
production, distribution,
marketing and consumption of
ultra-processed products
negatively affects society,
culture and the environment'

Argument used

In defence of the food industry

Examples of statements

'If everybody began eating only fresh and minimally processed foods, family farming would probably not meet the food demands of the population for a long time. Processed and ultra-processed foods are often an option for different situations and regions.' (Organization linked to the food industry)

'Sustainability in food production is a determining factor for the production of healthy food. Not only for now but for future generations. However, the guide addresses this issue in a dogmatic way, suppressing large-scale food production. Such statements do not match the current situation in the world, in which the population is growing and the cultivation techniques for largescale food production are needed. In addition, the guide disregards the existence of efforts aimed at minimizing the impact of food production on the environment. It should be stressed that not only the food chain is associated with damage to the environment.' (Individual)

'The author raises an issue that, although real, is not exclusively caused by agriculture or food processing. In this sense, this unilateralism confers on the food production sector something that is also the result of the petrochemical, textile, automotive, energy, electronics and pharmaceutical industries.' (Organization linked to the food industry)

'In order to reduce the environmental impact, many companies adopt measures such as the Recycling Centers programme, which since 2001 has allowed the consumer to the correctly recycle packaging, bottles, paper, plastic, aerosols, glass, metal and cooking oil.' (Organization linked to the food industry)

Refers to the section of the new food guide which says: 'Healthy eating is the result of a sustainable food system. Healthy eating patterns are possible only in food systems that protect and respect the natural environment where food is obtained'
Pointing out the need for the guide to deal with some issues more thoroughly
'It is also necessary to clarify that nowadays food problems are due to the existence of a food system that has high concentration of calories and low nutritional value. Improving food quality will depend on the regulations of this system and its transformation.' (Individual)

'We know that Brazil is the champion agrochemical use in food production, and if the purpose of this guide is to improve the diet of Brazilians, this point should be taken into account and examined further.' (Academic)

'There is talk of environment and ethics, but none about vegetarianism. Vegetarianism is a dietary practice that causes less damage to the environment and values ethics more at stages of food production.' (Individual)

'It is suggested to enhance the importance of sustainable water consumption: both regarding the choice of foods with less water impact, i.e. requiring the least amount of water for their production (e.g. large consumption of water for the production of meat) and choose food and products that do not pollute the water reservoirs during production, that is, those who are from agroecology.' (Organization linked to public interests) to prevent disease and promote health, giving food the characteristics of medication, and devalues the symbolic, social and cultural act of eating ${ }^{(18-22)}$. This approach to food and health places little value on the relationship between food and the ways in which it is processed, nor on the cultural contexts in which it is eaten ${ }^{(4)}$. The practical experience of growing, preparing and eating food is reduced to the nutrients it contains and their impact on health ${ }^{(4)}$. Another implication of medicalization is that it produces professionals who are extremely specialized in a particular subject, concentrating the power of knowledge in the hands of a few and making it too technical for the average person ${ }^{(23)}$. In 'nutritionism'(4), or 'nutritional scientism',(22), authority for eating is transferred from individuals to 'experts', which devalues popular knowledge and people's traditional food culture ${ }^{(24)}$. Contrary to the medicalization of food consumption, the new guide uses a qualitative approach to make communication with the population more accessible. This is in line with the opinions of Beardsworth and Keil ${ }^{(23)}$, that 'one has to consider limits on the application of rationalization to health and diet, as in the mundane routine of people, they are not equipped with devices to measure their food "consumption".

Participants in the consultation also made repeated use of the imperative of scientific evidence to justify their arguments. Although the use of science as a way of supporting positions is of course common in academia, it was observed that the food industry and their representatives also used science to defend their interests during the public consultation. Some key points should be taken into account 
when 'speaking in the name of science' in debates on policies and programmes in the area of food and nutrition. First, the existence of scientific evidence is not the only and obligatory principle in the implementation of policies ${ }^{(23)}$; furthermore, in the words of Lang et $a l .{ }^{(16)}$, 'sometimes the world cannot wait for evidence' and it may take a significantly long time to obtain the 'perfect' scientific evidence to support a proposed policy. Some evidence may also be impossible to obtain, as conducting randomized studies to verify the risk of ultra-processed foods on human health would be considered unethical. Second, like the medicalization argument, the scientific argument facilitates the perpetuation of asymmetric power relations between experts and the general population ${ }^{(23,25)}$. As was observed in this consultation, disproportionate value is placed on clinical and epidemiological science over other forms of knowledge, thus reducing the cultural dimensions of food and encouraging the population to be dependent on health professionals ${ }^{(23)}$. Another important implication of the scientific argument is the general belief that science is both objective and neutral, masking its role in the perpetuation of political and economic interests ${ }^{(25)}$. An example of this is the evidence generated from scientific research funded by the food industry and the ethical questions raised by the results. Conducting scientific research usually requires considerable financial investment, which facilitates the establishment of partnerships between researchers and private institutions. This conflict of interest is a threat to the neutrality of scientific research; a study conducted by Lesser et $a{ }^{(26)}$, which investigated the influence of research funding by the food industry on scientific studies on the health effects of milk, juices and soft drinks, found that the chance of a study presenting results favourable its sponsors was eight times higher when funded by the food industry than when funded in other ways. Other factors that affect this partnership between scientists and the food industry range from the way in which the study is designed, to contracts which specify that authorization for results to be released will be given only when they are favourable to the food industry ${ }^{(27)}$. According to Barnoya and $\mathrm{Nestle}^{(28)}$, Latin America is especially vulnerable to conflicts of interest related to nutritional science, and the authors point out the need to identify, limit and manage (or eliminate) the apparent and real conflicts until a more definitive solution to the question can be found. Both at national and international level, the food industry is always well represented in arenas dealing with laws, policies and programmes in the area of food and nutrition, and the asymmetrical power relationships that are noticeable in the discussions are evidence of the power of multinational food industries ${ }^{(16,29)}$

The risk discourse was an argument widely used during the consultation and focused mainly on risks related to the body (e.g. risk of obesity, microbiological contamination or dehydration). This emphasis reflected a feeling that the act of eating or not eating certain nutrients/foods can pose a health risk and for this reason should be quantified, measured, monitored and self-managed (i.e. by establishing food portions, making explicit the quantities of sugar/salt/fat considered to be a disease risk and the amount of water that should be consumed). The superficiality of the risk discourse as a way of promoting healthy eating means that it can be a less effective way of communicating with the population. The notion of risk undermines the concept of healthy eating, creates anxiety, doubt and confusion, disconnects people from their food culture and makes it difficult to trust health information, as food risks can be constantly revised or even reversed (e.g. eggs and cholesterol) ${ }^{(30)}$. The risk discourse makes us "virtual victims',(31) of probabilistic events related to health, often giving health professionals a normative, moralizing and hyper-preventive attitude to people's individual behaviour ${ }^{(32)}$. In addition, the risk discourse reinforces the unequal power relationship between professionals and the population by emphasizing scientific knowledge of the risks at the expense of the subjective ways in which risk is interpreted by individuals ${ }^{(23)}$. Special attention should be paid to the risk discourse when it classifies as a risk traditional culinary preparations that may have cultural value for the population, which was the case in the public consultation analysed here, as this can have an iatrogenic and counterproductive effect on public health interventions $^{(18)}$. Risk is something that is inherent in human life ${ }^{(33)}$, so it is important to be able to identify the risks that can and should be avoided, and to remember that the priority should be to examine the social and economic contexts in which these risks are most prevalent ${ }^{(34)}$.

Participants who advocated for the inclusion of vegetarianism in the guide approached the question of risk in its broader sense, going beyond individual risk centred on the body by discussing the environmental risk from the production of processed foods and the importance of a healthy food system. The opinions of these participants questioning the current food system reflect the position taken by $\operatorname{Beck}^{(35)}$ with regard to 'the risk society' and 'reflexive modernization'. According to this author, the social, political, economic and individual risks posed by industrialized society (such as environmental issues) have become a threat to civilization and need to be self-addressed and self-transformed by us all (what the author calls 'reflexive modernization'); the knowledge of experts is questioned and new views gain credence (for example, the vegetarian views in this consultation). The question of the environmental impact of the food system requires more incisive, intersectoral action, encompassing all forms of knowledge and all members of society ${ }^{(36)}$.

The food industry is a key player in addressing the environmental risks to which we are exposed and this issue has long been discussed within the industry itself, resulting in research into socially responsible technologies and actions that may mitigate negative environmental 
effects $^{(37)}$. However, in the public sphere, just as with the issue of chronic non-communicable diseases, environmental problems are treated more as threats than opportunities, and counteractive measures are limited by the need to remain financially competitive and to generate profit ${ }^{(16)}$. This attitude can be observed in the consultation analysis, with those representing the food industry adopting a defensive position, denying the environmental problems related to food production or using the social responsibility argument (such as highlighting their policies to recycle packaging) to show that they are taking action on environmental issues. Another challenge to the development of environmentally sustainable systems is the intellectual division in the science of nutrition, which can be divided into three different areas: biomedical, social and environmental ${ }^{(16)}$, divisions which were all evident in the consultation analysis. As these views represent different social and economic interests, the challenge is to reach a consensus in order to develop a fair food system and not simply to create new ideologies or new ecologically friendly food products ${ }^{(16)}$. In addition to the food industry and nutrition professionals, nongovernmental organizations and those linked to public interests also play a key role in environmental issues, by monitoring actions, educating and giving support to consumers, as well as reflecting their opinions ${ }^{(29)}$.

With regard to Theme 2, Different Perceptions about the Role and Need of Individuals, some participants (associations and organizations linked to nutrition) considered that individuals are largely responsible and free to make food choices, an argument traditionally used by the food industry ${ }^{(38)}$. Another argument along the same lines used by the food industry was that the market provides what consumers demand. First, this is a social myth, as it assumes a symmetrical power relationship between people and corporations ${ }^{(16)}$; and second, this kind of argument reflects a neoliberal view of consumer society, in which actions and their consequences are the sole responsibility of the individual, thus diverting attention from more systemic questions such as social inequality, the constant influence of the environment on food choices, the interference of the food industry in science and nutrition information, etc. ${ }^{(20,39)}$. This kind of message - that we are masters of our own destiny - leads to even more social individualization and increasingly prevents us from creating and implementing actions for the common $\operatorname{good}^{(40)}$. The statements made in the consultation regarding individuals as consumers are opposed to the concept of autonomy in health, which focuses on the co-responsibility of individuals for their health choices, and depends on external factors such as the economy, the political environment, the regulation of food advertising, food labelling with accurate information, etc. ${ }^{(41,42)}$. The definition of consumers for Lang et al. ${ }^{(16)}$ is also quite different from the neoliberal concept of the consumer adopted by some participants in this consultation. These authors use the term 'food citizens', viewing the population as able to actively pursue its rights and duties, and not simply as consumers of goods and services, for which non-governmental organizations play a fundamental role. In Brazil, the fight against hunger and the promotion of food and nutrition security have been part of the government agenda since $2003^{(43)}$, and the participation of members of the public in the formulation and implementation of federal policies has become increasingly important. Several government actions have been driven by partnerships with non-governmental organizations, helping to implement and strengthen programmes and policies in the area of food and nutrition, specifically with regard to malnutrition, obesity, the promotion of healthy eating, monitoring nutritional security, implementing intersectoral strategies and providing forums for the public to take part in policy-related discussions $^{(44)}$. In the consultation analysis, the large number of participants who defended the interests of the population is a positive point that should be emphasized. Compared with the 2003 public consultation on mandatory food labelling ${ }^{(45)}$, in which only $12 \%$ of participants defended the interests of the population, in this consultation there was evidence of growing public participation in debates related to food and nutrition in Brazil. Although this group of participants tended to agree with the new food guide, they also criticized it for failing to include certain issues, or for not examining other issues in sufficient depth, such as pesticides, GMO and organic food, food advertising, and the lack of discussion related to existing nutrition and food policies in Brazil. These points are of particular importance to the food and nutrition agenda in Brazil, so it is understandable that the participants tried to use the new food guide as a platform to express their opinions and to call for new measures to be taken.

The qualitative analysis of public consultations in the development of food guides can be very useful for predicting how the implementation of the material will proceed and especially who may seek to undermine the implementation of the new guide. Counteractive measures of this kind have already been taken, for example the 'Brazil Processed Food 2020' project ${ }^{(46)}$, which was created by organizations linked to the food industry to undermine the new food guide. Another example was an open letter posted online by an organization linked to nutrition academics, which questioned the scientific basis of applying the NOVA classification in the new guide. Countries such as the USA, which have also used this form of participation in the construction of their food guide ${ }^{(47)}$, may benefit from this type of research as well, as it provides insight into who the actors are and what kind of discourse takes place behind the scenes in the development of food and nutrition policies. This could be a useful example for organizations linked to public interests to plan mass-media campaigns that are more effective in raising awareness among the population and to pressure the 
government to ensure that the message of the new guide successfully reaches the population.

The process of open consultation conducted in Brazil to develop the new guide can also offer important lessons to other countries in Latin America which have developed and implemented their own food guides. Including a variety of actors in the discussion from the very start, such as organizations linked to public interests, is a form of virtuous cycle. It not only helps to attenuate the asymmetry of power that forms the background to discussions related to health and nutrition, but also helps those organizations to be more involved during the implementation of food guides, encouraging them to contribute to the success of the material. In Mexico ${ }^{(48)}$, there has recently been a great deal of scientific debate and consultation of experts to develop a new Mexican food guide, and very important points related to public health nutrition were addressed. Unfortunately, this country did not conduct an open consultation like the one in Brazil and this lack of involvement by the population and/or public organizations could represent a threat to the successful implementation of the food guide.

A strong point of the current study was the originality of the theme, which on the one hand explores the conflicts of interest when designing and implementing food and nutrition policies related to the application of a food processing-based classification system, and on the other hand analyses the participation of civil society in the development of a food guide, which to the best of our knowledge has not been explored in any other scientific publication.

A limitation of the study is the type of data used (documents), which does not always allow for all the forms of communication used by the participants to be recorded, such as body language and facial expression. However, the authors believe that the large number of contributions made by stakeholders to the public consultation has provided abundant information for the debate proposed in this article. Another limiting factor is that two of the authors participated directly and indirectly in designing the food guide that was submitted for consultation. However, to mitigate possible analytical bias, these authors did not participate in the data coding or the identification of themes.

\section{Conclusions}

Many different sectors of Brazilian society participated in the consultation for the new food guide and the issues raised showed two contrasting opinions on healthy eating: a reductionist argument and a holistic argument. There was a great deal of opposition to the use in the new food guide of a classification of foods based on the extent and purpose of their processing. It was noticed that resistance came mainly from the food industry and their representatives. Nevertheless, the classification of foods based on their processing was maintained in the new guide as a result of the political commitment of the Brazilian government to health promotion and the human right to healthy food. The authors hope that the present study will benefit all those directly or indirectly involved in this public consultation, encouraging them to expand their views on nutrition science and to communicate more effectively with the population. It is also expected to raise awareness of the ethical issues related to public health nutrition and to encourage different actors to be more proactive in building healthy food systems.

\section{Acknowledgements}

Financial support: This research received no specific grant from any funding agency in the public, commercial or notfor-profit sectors. Conflict of interest: Two of the authors participated directly or indirectly in designing the food guide which is the subject of this paper. Authorship: V.F.D. analysed the data and wrote the manuscript; K.J.M. participated in the data analysis; P.C.J. and J.-C.M. gave feedback and guided the development of the manuscript. All authors critically reviewed the manuscript and approved the final version submitted for publication. Ethics of buman subject participation: Not applicable.

\section{References}

1. Food and Agriculture Organization of the United Nations (2015) Food-based dietary guidelines. http://www.fao.org/ nutrition/nutrition-education/food-dietary-guidelines/en/ (accessed March 2015).

2. Tzeng MS (2008) From dietary guidelines to daily food guide: the Taiwanese experience. Asia Pac J Clin Nutr 17, Suppl. 1, 59-62.

3. Gibney MJ, Margetts BM, Kearney JM et al. (2004) Public Health Nutrition. Oxford: Blackwell Publishing.

4. Scrinis G (2013) Nutritionism: The Science and Politics of Dietary Advice. New York: Columbia University Press.

5. Mayes C \& Thompson DB (2014) Is nutritional advice morally indigestible? A critical analysis of the scientific and ethical implications of 'healthy' food choices discourse in liberal societies. Public Health Ethics 7, 158-169.

6. Willet WC \& Ludwig DS (2011) The 2010 Dietary Guidelines - the best recipe for health? N Engl J Med 365, 1563-1565.

7. Monteiro CA, Cannon G, Moubarac JC et al. (2015) Dietary guidelines to nourish humanity and the planet in the twenty-first century. A blueprint from Brazil. Public Health Nutr 18, 2311-2322.

8. Ministério da Saúde (Brasil), Secretaria de Atenção à Saúde, Departamento de Atenção Básica (2014) Guia Alimentar para a População Brasileira. Brasília: Ministério da Saúde.

9. Monteiro CA, Levy RB, Claro RM et al. (2011) Increasing consumption of ultra-processed foods and likely impact on human health: evidence from Brazil. Public Health Nutr 14, $5-13$.

10. Louzada ML, Baraldi LG, Steele EM et al. (2015) Consumption of ultra-processed foods and obesity in Brazilian adolescents and adults. Prev Med 81, 9-15.

11. Adams J \& White M (2015) Characterisation of UK diets according to degree of food processing and associations with socio-demographics and obesity: cross-sectional analysis of UK 
National Diet and Nutrition Survey (2008-12). Int J Behav Nutr Phys Act 12, 160.

12. Canella DS, Levy RB, Martins AP et al. (2014) Ultra-processed food products and obesity in Brazilian households (2008-2009). PLoS One 9, e92752.

13. Moubarac JC, Batal M \& Martins AP (2014) Processed and ultra-processed food products: consumption trends in Canada from 1938 to 2011. Can J Diet Pract Res 75, 15-21.

14. Monteiro CA, Cannon G, Levy R et al. (2016) Classificação dos alimentos. Saúde Pública. World Nutr 7, 1-3.

15. Ministério da Saúde (Brasil), Coordenação-Geral de Alimentação e Nutrição (2014) Relatório Final da Consulta Pública - Guia Alimentar para a População Brasileira. http://dab.saude.gov.br/ portaldab/guia_alimentar_populacao_brasileira.php (accessad March 2015).

16. Lang T, Barling D \& Caraher M (2009) Food Policy: Integrating Health, Environment and Society. Oxford: Oxford University Press.

17. Ritchie J, Spencer L \& O'Connor W (2003) Carrying out qualitative analysis. In Qualitative Research Practice: A Guide for Social Students and Researchers, pp. 219-262 [J Ritchie and J Lewis, editors]. London: SAGE Publications Ltd.

18. Walt G (2008) Health Policy: An Introduction to Process and Power. Johannesburg: Witwatersrand University Press.

19. Nettleton S (2013) The Sociology of Health and Illness. Cambridge: Polity Press.

20. Ferreira FR, Prado SD, Carvalho MCVS et al. (2015) Biopower and biopolitics in the field of food and nutrition. Rev Nutr 28, 109-119.

21. Clark J (2014) Medicalization of global health 3: the medicalization of the non-communicable diseases agenda. Glob Health Action 7, 24002.

22. Mayes C (2014) Medicalization of eating and feeding. In Encyclopedia of Food and Agricultural Ethics, pp. 1-8 [PB Thompson and DM Kaplan, editors]. Dordrecht: Springer Netherlands.

23. Beardsworth A \& Keil T (1997) Sociology on the Menu: An Invitation to the Study of Food and Society, p. 38. Abingdon: Routledge.

24. Gracia-Arnaiz M (2007) Comer bien, comer mal: la medicalización del comportamento alimentario. Salud Publica Mex 49, 236-242.

25. Castoriadis C \& Cohn-Bendit D (1981) Da Ecologia a Autonomia. São Paulo: Editora Brasiliense.

26. Lesser LI, Ebbeling CB, Goozner M et al. (2007) Relationship between funding source and conclusion among nutritionrelated scientific articles. PLOS Med $\mathbf{4}$, e5.

27. Katan MB (2007) Does industry sponsorship undermine the integrity of nutrition research? PLoS Med $\mathbf{4}$, e6.

28. Barnoya J \& Nestle M (2016) The food industry and conflicts of interest in nutrition research: a Latin American perspective. J Public Health Policy 37, 552-559.

29. Lang T \& Heasman (2015) Food Wars: The Global Battle for Mouths, Minds and Markets. London: Earthscan.

30. Azevedo E (2015) Liberem a dieta. Demetra 10, 717-727.
31. Vaz P (2012) Corpo e risco. In Que Corpo é Esse? Novas Perspectivas, pp. 101-111 [N Villaça, F Góes and E Kosovski, editors]. Rio de Janeiro: Mauad.

32. Castiel LD (2011) Dédalo e os dédalos: identidade cultural, subjetividade e os riscos a saúde. In: Promoção da Saúde: Conceitos, Reflexões, Tendências, pp. 79-95 [D Czeresnia and CM Freitas, editors]. Rio de Janeiro: Editora FioCruz.

33. La Mendola S (2005) O sentido do risco. Tempo Social, Rev Sociol USP 17, 59-91.

34. Caponi S (2011) A saúde como abertura ao risco. In Promoção da Saúde: Conceitos, Reflexões, Tendências, pp. 55-77 [D Czeresnia and CM Freitas, editors]. Rio de Janeiro: Editora FioCruz.

35. Giddens A, Beck U \& Lash S (1995) Modernizacao Reflexiva - Politica, Tradição e Estética na Ordem Social Moderna. São Paulo: Editora Unesp.

36. Azevedo E \& Pelicioni MCF (2011) Promoção da saúde, sustentabilidade e agroecologia: uma discussão intersetorial. Saude Soc 20, 715-729.

37. Nestle M (2005) Soda Politics: Taking on Big Soda (and Winning). New York: Oxford University Press.

38. Nestle M (2007) Food Politics. London: University of California Press.

39. Giesler M \& Veresiu A (2014) Creating the responsible consumer: moralistic governance regimes and consumer subjectivity. I Consum Res 41, 840-857.

40. Herman ES \& Chomsky N (2002) Manufacturing Consent: The Political Economy of the Mass Media. New York: Pantheon Books.

41. Brownell KD, Kersh R, Ludwig DS et al. (2010) Personal responsibility and obesity: a constructive approach to a controversial issue. Health Aff (Millwood) 29, 379-387.

42. Campos RTO \& Campos GWS (2006) Co-construção de autonomia: o sujeito em questão. In Tratado de Saúde Coletiva, pp. 669-688 [GWS Campos, MCS Minayo, M Akerman et al, editors]. São Paulo: Ed. Hucitec.

43. Burlandy L (2011) A atuação da sociedade civil na construção do campo da Alimentação e Nutrição no Brasil: elementos para reflexão. Cienc Saude Colet 16, 63-72.

44. Rocha C, Jaime PC \& Rea MF (2016) How Brazil's political commitment to nutrition took shape. In Global Nutrition Report 2016: From Promise to Impact: Ending Malnutrition by 2030, pp. 11-12. Washington, DC: International Food Policy Research Institute.

45. Davies V \& Jaime PC (2017) Mandatory food labeling of trans fat acids: qualitative analysis of the public consultation. Interface (Botucatu) 21, 5-8.

46. Oliveira MSS \& Silva-Amparo L (2017) Food-based dietary guidelines: a comparative analysis between the Dietary Guidelines for the Brazilian Population 2006 and 2014. Public Health Nutr (Epublication ahead of print version).

47. Millen BE, Abrams S, Adams-Campbell L et al. (2016) The 2015 Dietary Guidelines Advisory Committee Scientific Report: development and major conclusions. Adv Nutr 16, 438-444.

48. Pérez-Escamilla R (2016) The Mexican Dietary and Physical Activity Guidelines: moving public nutrition forward in a globalized world. J Nutr 146, issue 9, 1924S-1927S. 